\title{
The 'Long-Term' Effects of Universal School-based Anxiety Prevention Trials: A Systematic Review
}

*Samuel M. Waldron ${ }^{\mathrm{a}}$, Paul Stallard ${ }^{\mathrm{a}}$, Rebecca Grist ${ }^{\mathrm{a}}$, Catherine Hamilton-Giachritsis ${ }^{\mathrm{a}}$

${ }^{a}$ Department of Psychology, University of Bath, UK

* Corresponding author

samuel.waldron@,bath.edu

Department of Psychology, Clinical Psychology Programme, University of Bath, Claverton Down, BA2 7AY, United Kingdom

p.stallard@bath.ac.uk

r.grist@bath.ac.uk

c.hamilton-giachritis@bath.ac.uk 


\begin{abstract}
Objective: Previous reviews demonstrate that universal school-based anxiety prevention programs are generally effective in the short-term, but have not yet provided a clear evaluation of the longer-term effects. This review focuses exclusively on randomized controlled trials (RCTs) of universal school-based anxiety prevention programs that included a follow-up at 12-months or beyond.

Method: In total, 359 references from previous reviews in the field were screened; PubMed and PsychInfo were also systematically searched. Eight studies met criteria (each based on cognitive-behavioural principles) comprising 7522 children aged nine-18 years. Risk of bias in most studies was high, thus a formal meta-analysis was not conducted.

Results: Three of the eight studies reported greater reductions in anxiety symptomology in the prevention group compared to the control group at post-intervention (immediate effect), and each of these studies also reported maintenance of this effect at 12-month follow-up. Two further studies reported a 'delayed' effect at 12-month follow-up. Each of these five studies was evaluating the FRIENDS program, and estimated effect sizes at 12-months follow-up varied from 0.2 to 0.69 (Hedges $g$ ). The final three studies reported no immediate or longterm effects.

Conclusions: The findings from this review suggest that the effects of some universally delivered school-based anxiety prevention trials can last up to 12-months, but this may depend on various factors (including program-type). It was not possible to draw firm conclusions regarding the influence of delivery mode (teacher versus health professional), parent sessions or child booster sessions. Further high quality RCTs with long-term follow-up periods are needed.
\end{abstract}

Keywords: Anxiety; prevention; schools; universal; long-term; public health 


\section{Introduction}

Anxiety disorders often start in childhood or adolescence (Costello, Egger, \& Angold, 2005), and can lead to significant distress, poor educational outcomes and comorbid mental and physical health problems (Donovan \& Spence, 2000). Studies estimate childhood prevalence rates of between 10-15\% (Snyder et al., 2009) and lifetime prevalence rates close to $30 \%$ (Kessler et al., 2005). Psychological interventions are available, with average treatment effect sizes $(d)$ in the moderate region of 0.6 (Reynolds, Wilson, Austin, \& Hooper, 2012). However, cross-sectional research suggests that at any given time, as few as $18 \%$ of the children and adolescents that would meet criteria for an anxiety disorder are accessing mental health services (Essau, 2005). In response to this public health priority, there has been a proliferation of studies published since the turn of the century evaluating psychological programs designed to prevent the development of anxiety disorders in childhood and adolescence (Ahlen, Lenhard, \& Ghaderi, 2015).

Most anxiety prevention programs utilise cognitive behavioural theory, focussing on emotional and cognitive awareness, positive self-talk/imagery, attentional training, psychoeducation, relaxation, problem solving, exposure, behayioural experiments and cognitive restructuring (Stallard, 2010). Theoretically, it is argued that promoting protective/resilience factors such as individual coping skills can help counteract risk factors such as behavioural inhibition, parental anxiety and stressful life events (Donavan \& Spence, 2000). Young people who have experienced anxiety prevention programs of this nature are thought to be less likely to develop anxiety problems in response to stressful life events due to the deployment of adaptive coping strategies (Barrett \& Turner, 2001).

Schools are well placed to host such programs because they have access to large numbers of young people, many of which will be at risk of developing anxiety disorders (Barrett \& Pahl, 2006). Programs can be rolled out 'universally' to all pupils, 'selectively' to those pupils deemed at higher risk, and also to pupils 'indicated' as having elevated subthreshold symptoms (Haggerty \& Mrazek, 1994). Although some evidence suggests that selective or indicated programs yeild better results for the prevention of depression (Merry et al., 2011), a recent large-scale meta-analytic review conducted by Werner-Seidler, Perry, Calaer, Newby and Christensen (2017) reported similar effect sizes for universal and selective/indicated school-based anxiety prevention programs. Universal programs can be expensive and time-consuming to set up, but they are also perceived as less stigmatizing (Fisak, Richard, \& Mann, 2011), can overcome difficulties associated with screening for risk 
(Donovan \& Spence, 2000) and can reach all children regardless of symptomology (MasiaWarner, Nangle, \& Hansen, 2006). Recruitment, transport and drop-out rates are less of an issue when running universal programs to all pupils in a school, and universal programs can be weaved into the school curriculm teaching skills that will be useful to all participants, not just those with sub-clinical symptoms (Barrett \& Pahl, 2006).

Debate is ongoing as to whether schools should routinely be running universallydelivered anxiety prevention programs, and the existing reviews in this area have yet to provide clear data regarding the 'long-term' effects. For example, although Werner et al. (2017) suggest that small (0.13) effect sizes were evident for anxiety prevention programs at 12-months follow-up, this represents combined data aggregated across universal, selective and indicated trials. Several broad-ranging reviews already exist that are fully inclusive of indicated, selective and universal programs, but few focus in suffeient detail on the long-term effects of universal school-based anxiety prevention programs. For example, Neil and Christensen (2009) reviewed the effectiveness of universal, selective and indicated schoolbased anxiety prevention programs, and of the 16 universal trials inlcluded in their review, 11 reported positive post-intervention effects (with effect sizes ranging from 0.31-1.37). Three of these trials reported a long-term effect at 12-months, but most trials were limited to shortterm follow-up only. Therefore little can be concluded from these reviews regarding the longterm effectiveness of universally delivered school-based anxiety prevention programs.

Stockings et al. (2016) recently conducted a meta-analysis of 146 anxiety and depression prevention trials, and small meta-effects for the 24 universal anxiety prevention trials were identified at post-intervention (0.16) through to 6-9 months follow-up (0.13). However, it is not possible to partial out the results from school and community-based trials. Teubert and Pinquart (2011) conducted a meta-analysis of 65 anxiety prevention studies, reporting small meta effect size estimates of 0.22 at post-intervention and 0.19 at short-term follow-up. However, these data are aggregated across universal, selective and indicated trials, are not confined to school-based studies, and do not include longer-term follow up data. The reviews conducted by Fisak et al. (2011) and Ahlen et al. (2015) have similar limitations. In summary, although previous reviews suggest that the general effects of different types of anxiety prevention programs may last up to six-nine months (e.g., Stockings et al., 2016; Werner-Seidler et al., 2017), these reviews do not provide specific details about the long-term effects of universally delivered school-based programs. 
Therefore this review focuses exclusively on universally delivered school based anxiety prevention trials that have follow-up data of at least 12-months (and beyond). This will provide public policy and education colleagues with useful information regarding true duration effects and how regularly 'booster' sessions might be needed. This focus is important because some authors have argued that the benefits of prevention programs may not be seen until the recipients have had the opportunity to pass through a period of 'elevated risk' (Gillham, Shatté, \& Reivich, 2001). An analysis of how many studies reported 'delayed' effects (i.e., effects that do not emerge until several months after the prevention program finishes) will provide an estimate as to the extent to which previous reviews focusing only on short-term 'prevention' effects may have missed potential longer-term benefits.

An a-priori decision was taken to focus on randomised controlled trials (RCTs) in the current review, because public health colleagues are looking for high quality evidence using 'gold standard' methodology. A decision was also taken to focus on programs including direct work with the pupils, because this is often the main approach available to schools. It is acknowledged that by focussing on RCTs of programs that emphsise direct work with children/adolescents, this review is likley to capture mostly (if not entirely) cognitivebehavioural prevention programs.

Based upon the tentative conclusions drawn by previous reviews in the field, it was hypothesised that a small effect size estimate will be found at the 12-month follow-up for the majority of studies included in this review. No specific predictions were made regarding the influence of delivery mode (teacher versus health professional), parent sessions or child booster sessions, or whether differential results will be observed according to gender and age, but these factors will be explored. Because several of the large-scale reviews already published in this area have captured a wide scope of studies, this review will inspect the references cited by these reviews first before conducting a new database search to check for other studies not already captured.

\section{Method}

\subsection{Inclusion Criteria}

In order to focus this review on the long-term effects of universal school-based anxiety prevention trials, the following inclusion criteria were developed:

- To be included in this review the study design must have been a randomised controlled trial (RCT) 
- Population: children and adolescents aged 5-18 years at the beginning of the trial; the setting must have been in school (during normal school hours)

- Intervention: a universal program offered to all pupils in the class/school/year group citing anxiety as a primary or dual prevention target (with a clear theoretical rationale); some direct work must have been undertaken with the children as part of the program

- Comparison group: either a wait-list control, attention-control or no intervention control

- Outcome measures: standardised child-completed self-report questionnaires of anxiety symptomology (taken pre, post and a minimum of 12-months following intervention).

- Only peer-reviewed journal articles published in the English language between 1980 and January 2017 were considered.

\subsection{Search Protocol}

Step one was to screen all 359 publications identified by the six key reviews noted in the introduction against the inclusion criteria (Ahlen et al., 2015; Fisak et al., 2011; Neil \& Christensen, 2009; Stockings et al., 2016; Teubert \& Pinquart, 2011; Werner-Seidler et al., 2017). Removing duplicates revealed 178 different publications. Of these, 147 were excluded based on title or abstract alone, For the remaining 31 publications, the full text was accessed because it was not possible to assess eligibility based on title and abstract alone. The PRISMA flow-chart illustrated in Figure 1.1 provides an overview of this process. The first author (SW) and research assistant (RG) conducted this process separately and reached the same conclusion for $97 \%$ of the 178 separate publications (yielding a Cohen's Kappa of .75). Following inter-rater discussion to resolve five discrepancies, 11 publications were judged eligible for the current review. 


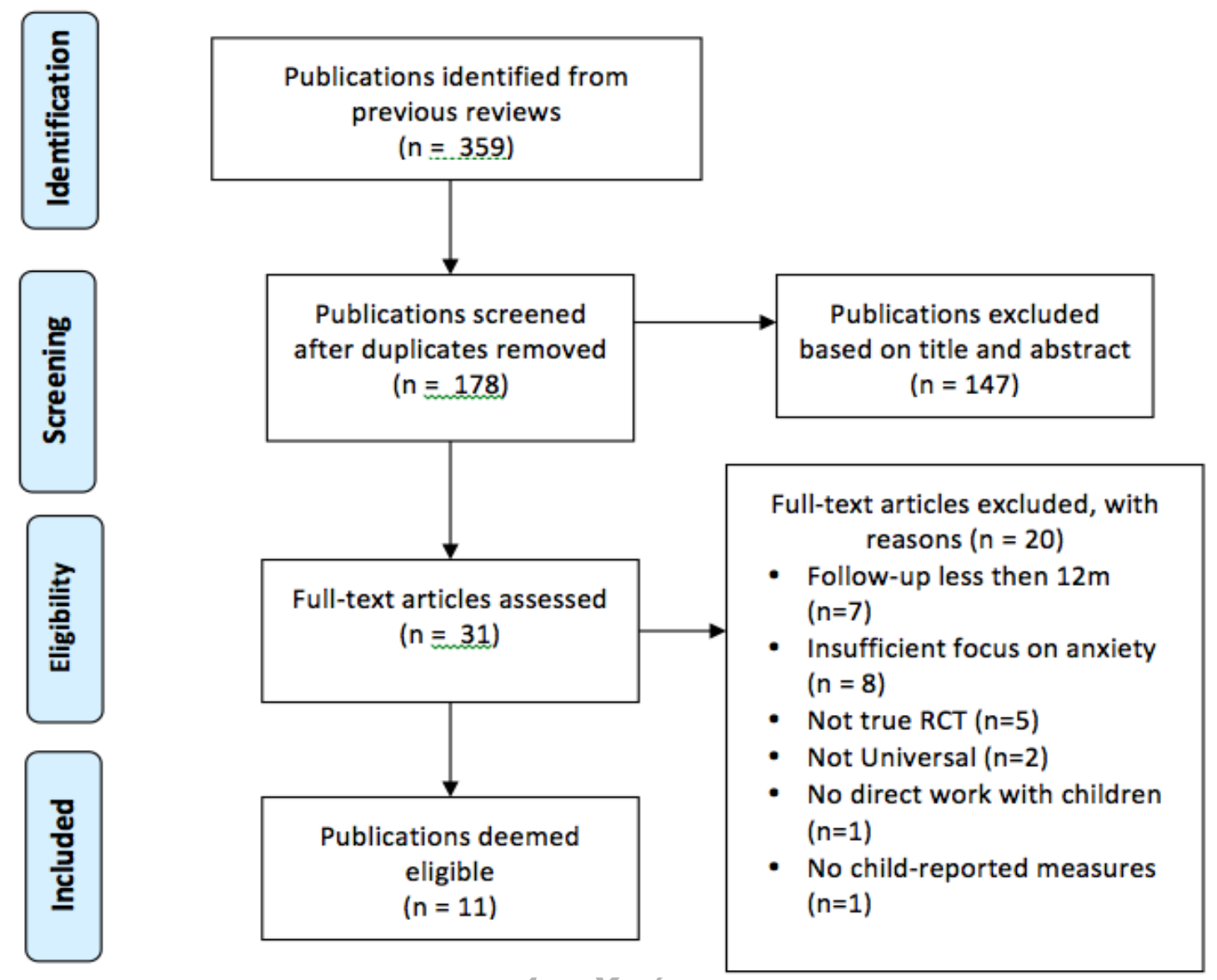

Figure 1.1. PRISMA flow-chart depicting step one of the search protocol

In order to check whether any additional studies could be identified via a new systematic search, step two involved carrying out database searches on PsychNet and PubMed and screening allidentified publications against the same inclusion criteria. The PsycNet terms developed in collaboration with a process expert were: 'school OR universal OR adolescent OR child OR children OR youth OR teen OR teenager' AND 'prevention OR preventative' AND 'anxiety OR anxious'. The PubMed terms developed in collaboration with a process expert were: "school” OR "universal" OR “adolescent” OR “child” OR “children” OR “youth” OR “teen” OR “teenager” AND “prevention” OR “preventative” AND "anxiety" OR “anxious". The searches were performed at the 'title and abstract' level.

The PsychNet search yielded 943 publications and the PubMed search yielded 1023 publications. SW and RG screened all publications separately and excluded the vast majority of publications based on abstract/title alone, or because the study had already been screened in step one of the search protocol. SW and RG accessed a total of eight previously unscreened full-text articles. After discussion, only one of these was deemed to meet the inclusion criteria for the current review. This study had not been picked up by the previous 
broad-ranging reviews in this area because it was published after their searches had taken place.

\subsection{Data Extraction}

For the purpose of this review, linked publications drawing on the same participants were collapsed yielding eight 'studies' in total. For each of these studies, the information and data were extracted by SW and checked by RG. Any differences were resolved by discussion and re-examination of the full text article.

\subsection{Risk of Bias}

The Cochrane Collaboration 'Risk of Bias' tool (Higgins \& Green, 2011) was used to assess the quality of each of the eight studies included in the current review. SW and RG independently allocated a code of Low Risk, High Risk or Unsure (when insufficient information was provided by the published article to make a judgment) to each of the following categories: allocation sequence generation; sequence concealment; reporting of incomplete data; selective reporting of data; blinding of participants and personnel; blinding of outcome assessment; and other possible risks of bias. Overall, 77\% of SW and RG's 56 code allocations were identical, yielding a Cohen's Kappa of .64. Each of the 13 discrepancies was resolved via discussion and re-examination of the full-text article. Where SW and RG agreed that insufficient information was provided by the published article to make a risk of bias judgment for a particular category, a clarification request was emailed to the corresponding author. Seven of the eight corresponding authors were contacted in this way and two responded with the information requested. In all other instances, a score of two (representing the category 'unsure') was retained for the risk of bias rating.

\subsection{Effect Size Calculations}

In order to compare the outcome data of the studies included in this review, standardized effect size estimates (ES) were calculated for each study (where possible), representing the difference between the prevention and control group anxiety symptomology at each time point. Cohen's $d$ (Cohen, 1988) was calculated first by subtracting the mean prevention group score from the mean control group score and dividing by the pooled standard deviation. These statistics were then transformed into Hedges' $g$ (Hedges, 1981) to ensure unbiased conservative estimates with an adjustment for small sample sizes. Positive ES estimates indicate that the intervention group improved more than the control group on a 
given measure. An ES of .20 is generally considered small, whereas an ES of .50 is considered moderate and an ES of .80 is considered large (Cohen, 1988). Only three of the eight studies included in this review (38\%) published the data needed to calculate these effect sizes. Raw mean, standard deviation and sample size data were requested from the corresponding authors of the other five studies, but none was returned.

\section{Results}

The results section first describes key study characteristics (including quality), before reviewing anxiety prevention data and concluding with a brief summary of secondary outcome data. In terms of anxiety prevention data, the focus will be on symptomology rather than diagnosis, because comparable data were available across all studies. Key study details are summarised in Table 1.1.

\subsection{Study Characteristics and Quality}

All of the eight studies included in this review evaluated anxiety prevention programs based on cognitive-behavioural principles. Five of the eight studies $(63 \%)$ evaluated the FRIENDS program, which was developed by Barrett, Lowry-Webster and Holmes (1999) and aims to teach children techniques in relaxation, cognitive restructuring, attentional training, parent-assisted exposure and peer support. Three of these studies were conducted in Australia by the program developers (Barrett, Lock, \& Farrell, 2005; Lock \& Barrett, 2003; Lowry-Webster, Barrett, \& Lock, 2003), one was conducted in Germany (Essau, Conradt, Sasagawa, \& Ollendick, 2012) and one was conducted in the UK (Stallard et al., 2014). Two of the other three studies evaluated the Aussie Optimism Program (AOP), which was developed by Rooney, Pike and Roberts (2000) and aims to teach children to identify and challenge negative thoughts and feelings about the self, current life circumstances and the future. Both of these trials were conducted in Australia by the developers (Roberts et al., 2010; Rooney, Hassan, Kane, Roberts, \& Nesa, 2013). The remaining study evaluated the ECOUCH program, which was developed by Calear, Christensen, Griffiths and Mackinnon (2013) and aims to teach children cognitive behavioural techniques and relaxation. This trial was conducted in Australia by the program developers (Calear et al., 2016). Only the ECOUCH program was delivered online. Teachers delivered the interventions in three of the studies (38\%), health professionals delivered the interventions in another three of the studies and two of the studies compared teacher and health professional delivery. 
The eight studies included in this review cover an age range of nine to 18 years (although the focus of most of the studies was on primary school aged children). Slightly more female than male participants were recruited into most of the studies. Sample sizes ranged from 496 to 1767 participants when the trial began, totalling 7522 children across all studies. In terms of fidelity, five of the eight studies (63\%) assessed randomly chosen sessions, two studies relied upon facilitator 'self-report' and Calear et al. (2016) used computer activity logs because the program was delivered online. Six of the eight studies (75\%) included a follow-up measure at 12-months, two included a follow-up measure at 18 months, one included follow-up at both 24 and 36-months, and one included follow-ups at 30, 42 and 54-months.

Table 1.2 indicates that the eight studies included in this review generally suffer from high risk of bias. The studies conducted by Stallard et al. (2014) and Rooney et al. (2013) yielded the lowest risk of bias (both scoring 11/21), whereas the studies conducted by Barrett et al. (2005), Lock and Barrett (2003) and Lowry-Webster et al.(2003) each yielded the highest risk of bias scores (17/21). Attritions rates were generally less than $20 \%$, with the exception of Essau et al. (2012) and Calear et al. (2016) where the attrition rates were 52\% and $61 \%$ respectively (yielding reduced sample sizes of 309 and 687 respectively at the 12 month follow-up). Only the two most recent studies included a clear power analysis (Calear et al., 2016; Stallard et al., 2014). None of the studies included in this review included an intervention control group. 
Table 1.1

Overview of the Eight Studies Included in this Review

\begin{tabular}{|c|c|c|c|c|c|c|c|c|c|c|c|}
\hline Study & $\begin{array}{l}\text { Program \& } \\
\text { country }\end{array}$ & Focus & $N$ & $\begin{array}{l}\text { Age \& } \\
\text { gender }\end{array}$ & Delivery & Sessions & Hrs & $\begin{array}{c}\text { Key } \\
\text { measures }\end{array}$ & Control & $\begin{array}{c}\text { LT } \\
\text { follow } \\
\text { up }(s) \\
\end{array}$ & $\begin{array}{c}L T \\
\text { attrition }\end{array}$ \\
\hline Barrett et al. (2005) & $\begin{array}{l}\text { FRIENDS, } \\
\text { Australia }\end{array}$ & Anxiety & 692 & $\begin{array}{l}9-10 \& 14-16 \\
(51 \% \text { male })\end{array}$ & $\begin{array}{l}\text { Face-to-face } \\
\text { (MHP) }\end{array}$ & $\begin{array}{c}10 \text { child, } 2 \\
\text { booster, } 4 \text { parent }\end{array}$ & 18 & $\begin{array}{l}\text { SCAS } \\
\text { CDI }\end{array}$ & $\mathrm{NI}$ & $12 \mathrm{~m}$ & $18 \%$ \\
\hline Calear et al. (2016) & $\begin{array}{l}\text { E-COUCH, } \\
\text { Australia }\end{array}$ & Anxiety & 1767 & $\begin{array}{c}12-18(31 \% \\
\text { male })\end{array}$ & $\begin{array}{l}\text { Online } \\
\text { (T v MHP } \\
\text { guided) }\end{array}$ & & 3.5 & $\begin{array}{l}\text { SCAS-GAD } \\
\text { SAS-A } \\
\text { GAD-7 } \\
\text { CES-D }\end{array}$ & WL & $12 \mathrm{~m}$ & $61 \%$ \\
\hline Essau et al. (2012) & $\begin{array}{l}\text { FRIENDS, } \\
\text { Germany }\end{array}$ & Anxiety & 638 & $\begin{array}{l}9-12(54 \% \\
\text { male })\end{array}$ & $\begin{array}{r}\text { Face-to- } \\
\text { (G) }\end{array}$ & $\begin{array}{l}\text { ild, } 2 \\
4 \text { parent }\end{array}$ & 14 & $\begin{array}{l}\text { SCAS } \\
\text { RCADS }\end{array}$ & WL & $12 \mathrm{~m}$ & $52 \%$ \\
\hline $\begin{array}{l}\text { Lock \& Barrett }(2003) \text {; } \\
\text { Barrett et al. (2006) }\end{array}$ & $\begin{array}{l}\text { FRIENDS, } \\
\text { Australia }\end{array}$ & Anxiety & 977 & $\begin{array}{c}9-10 \& 14-16 \\
(50 \% \text { male })\end{array}$ & $\begin{array}{c}\text { Face-to-face } \\
(\mathrm{MHP})\end{array}$ & $\begin{array}{c}10 \text { child, } 2 \\
\text { booster, } 4 \text { parent }\end{array}$ & 18 & $\begin{array}{l}\text { SCAS } \\
\text { RCMAS } \\
\text { CDI }\end{array}$ & WL & $\begin{array}{l}12 \mathrm{~m} \\
24 \mathrm{~m} \\
36 \mathrm{~m}\end{array}$ & $13 \%$ \\
\hline $\begin{array}{l}\text { Lowry- Webster et al. } \\
(2003)\end{array}$ & $\begin{array}{l}\text { FRIENDS, } \\
\text { Australia }\end{array}$ & Anxiety & 504 & $3(47 \%$ & $\begin{array}{l}\text { Face-to-face } \\
\qquad(\mathrm{T})\end{array}$ & $\begin{array}{c}10 \text { child, } 2 \\
\text { booster, } 3 \text { parent }\end{array}$ & 15 & $\begin{array}{l}\text { SCAS } \\
\text { RCMAS } \\
\text { CDI }\end{array}$ & WL & $12 \mathrm{~m}$ & $21 \%$ \\
\hline Roberts et al. (2010) & $\begin{array}{c}\text { AOP, } \\
\text { Australia }\end{array}$ & $\begin{array}{l}\text { Anxiety \& } \\
\text { depression }\end{array}$ & & & $\begin{array}{l}\text { Face-to-face } \\
\text { (T) }\end{array}$ & 20 child & 20 & $\begin{array}{l}\text { RCMAS } \\
\text { CDI }\end{array}$ & $\mathrm{NI}$ & $18 \mathrm{~m}$ & $12 \%$ \\
\hline $\begin{array}{l}\text { Rooney et al. } \\
(2013 a, b) ; \text { Johnstone et } \\
\text { al. }(2014)\end{array}$ & $\begin{array}{c}\text { AOP, } \\
\text { Australia }\end{array}$ & Anxiety \& & 9 & $\begin{array}{c}9-10(51 \% \\
\text { male })\end{array}$ & $\begin{array}{l}\text { Face-to-face } \\
(\mathrm{T})\end{array}$ & 10 child & 10 & $\begin{array}{l}\text { SCAS } \\
\text { CDI }\end{array}$ & $\mathrm{NI}$ & $\begin{array}{l}18 \mathrm{~m} \\
30 \mathrm{~m} \\
42 \mathrm{~m} \\
54 \mathrm{~m}\end{array}$ & $14 \%$ \\
\hline Stallard et al. (2014) & $\begin{array}{c}\text { FRIENDS, } \\
\text { UK }\end{array}$ & & 1448 & $\begin{array}{c}9-10 \\
\text { (46\% male) }\end{array}$ & $\begin{array}{l}\text { Face-to-face } \\
\text { (T v MHP) }\end{array}$ & 9 child & 9 & RCADS & $\mathrm{AC}+\mathrm{NI}$ & $12 \mathrm{~m}$ & $8 \%$ \\
\hline
\end{tabular}

Delivery: MHP = Mental Health Professional; T = Teacher; G = Graduate student. Measures: SCAS = Spence Children's Anxiety Scale; GAD = Generalized Anxiety Disorder; RCADS

= Revised Children's manifest Anxiety Scale; CDI = Children's Depression Inventory; SASA = Social Anxiety Scale for Adolescents ; CESDS = Centre for Epidemiological Studies

Depression Scale; RCMAS = Revised Children's Manifest Anxiety Scale. Control: WL = Wait-List Control; NI = No Intervention Control; AC = Active Control 
Table 1.2

Risk of Bias Summary

\begin{tabular}{|c|c|c|c|c|c|c|c|c|}
\hline Study & $A$ & $B$ & $C$ & $\bar{D}$ & $\bar{E}$ & $F$ & $G$ & $\begin{array}{c}\text { Total } \\
(\min =7, \max =21)\end{array}$ \\
\hline Barrett et al. (2005) & 2 & 2 & 3 & 2 & 3 & 2 & 3 & 17 \\
\hline Calear et al. (2016) & 1 & 1 & 3 & 1 & 3 & 3 & 3 & 15 \\
\hline Essau et al. (2012) & 2 & 2 & 3 & 1 & 3 & 2 & 3 & 16 \\
\hline $\begin{array}{l}\text { Lock \& Barrett } \\
(2003) \text {; Barrett et } \\
\text { al. (2006) }\end{array}$ & 2 & 2 & 3 & 2 & 3 & 2 & 3 & \\
\hline $\begin{array}{l}\text { Lowry- Webster et } \\
\text { al. }(\mathbf{2 0 0 3 )}\end{array}$ & 2 & 2 & 3 & 2 & 3 & 2 & & 17 \\
\hline Roberts et al. (2010) & 2 & 2 & 3 & 2 & 3 & 1 & & 16 \\
\hline $\begin{array}{l}\text { Rooney et al. } \\
(2013 a, b) ; \\
\text { Johnstone et al. } \\
(2014)\end{array}$ & 1 & 1 & 1 & 1 & 3 & & & 11 \\
\hline Stallard et al. (2014) & 1 & 1 & 1 & 1 & 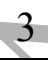 & 1 & 3 & 11 \\
\hline
\end{tabular}

$\mathrm{A}=$ Random sequence generation; $\mathrm{B}=$ Allocation concealment; $\mathrm{C}$ = Incomplete outcome

Data; $\mathrm{D}=$ Selective reporting; $\mathrm{E}=$ Blinding of participants and personnel; $\mathrm{F}=$ Blinding of outcome assessment; $\mathrm{G}=$ Other sources of bias; 1 = low risk; $2=$ unclear; 3 = high risk

\subsection{Long-term Anxiety Prevention Effects}

A formal meta-analysis was not conducted because of the relatively small number of studies included in this review and also the high risk of bias present in most of these studies. Table 1.3 provides an overview of the key anxiety prevention effects for each study ${ }^{1}$. Three of the eight studies included in this review reported greater reductions in anxiety symptomology in the prevention group compared to the control group at post-intervention (immediate effect) and each of these studies also reported maintenance of this effect at 12-months follow-up. Two studies reported limited or no immediate effect with a 'delayed' effect at 12-months follow-up. Estimated effect sizes at 12-months follow-up varied from 0.2 to 0.69 (Hedges $g$ ) and these effects were reported for the SCAS for four studies and the RCADS for one study. Only one of these studies reported an anxiety prevention effect beyond 12-months and this

\footnotetext{
${ }^{1}$ The effect size estimates provided in parentheses are for the difference between the prevention and control group at each time point. Only three of the studies (38\%) provided sufficient information to calculate relevant estimated effect sizes.
} 
was limited to the younger of the two age groups recruited. The other three studies reported no post-intervention or longer-term effects.

Although it was not possible to conduct a meta-analysis analysis of whether prevention outcomes were associated with particular study characteristics, it is worth noting that each of the five studies that reported a prevention effect at 12-months was evaluating the FRIENDS program (two of these studies were conducted outside of Australia by researchers not involved in the development of the program). However, an important caveat is that four of these studies were deemed to have high risk of bias (scores of 16 or 17/21). Each of the five studies reporting anxiety prevention effects at 12-months provided approximately ten child sessions, but it is worth noting that Stallard et al. (2014) reported prevention effects (albeit with a small effect size) without the use of parent or child booster sessions. Essau et al. (2012) explored parental attendance at allocated sessions and reported that this did not influence anxiety prevention data.

Long-term prevention effects were generally more likely to be reported by studies that evaluated delivery by health professionals/graduates than teachers and Stallard et al. (2014) found significant long-term prevention effects only when delivered by health professionals (not teachers). However, one study (Lowrey-Webster et al., 2003) did report 12-month prevention effects using teacher delivery. In terms of the total number of intervention hours provided, the studies reporting long-term prevention effects ranged from nine to 18 hours, with slightly larger effect sizes reported by the studies providing more intervention hours. However, a high number of intervention hours was not sufficient to yield long-term prevention effects (cf.Roberts et al., 2010). Results did not differ according to sample size or control type.

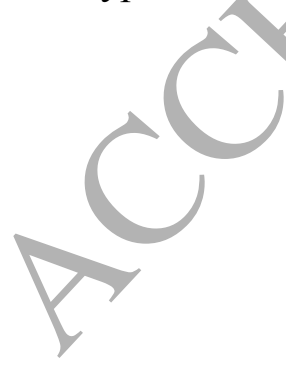


Table 1.3

Anxiety Prevention Outcomes ( available effect size estimates in parentheses)

\begin{tabular}{|c|c|c|c|c|}
\hline Study & Summary & $\begin{array}{c}\text { Post- } \\
\text { intervention }\end{array}$ & $12 m$ & $>12 m$ \\
\hline $\begin{array}{l}\text { Barrett et al. } \\
(2005)\end{array}$ & $\begin{array}{l}\text { Only at } 12 \mathrm{~m} \text { was a significant difference } \\
\text { found between the IG and CG (for both } \\
\text { age groups recruited). }\end{array}$ & N.S & $\begin{array}{c}\text { Sig } \\
\text { effect }^{\mathrm{a}}\end{array}$ & - \\
\hline $\begin{array}{l}\text { Calear et al. } \\
(2016)\end{array}$ & $\begin{array}{l}\text { No significant differences were found } \\
\text { between the CG and either the teacher- } \\
\text { led IG or the health professional-led IG } \\
\text { at any time point. }\end{array}$ & N.S & N.S & 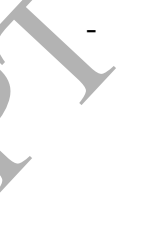 \\
\hline $\begin{array}{l}\text { Essau et al. } \\
(2012)\end{array}$ & $\begin{array}{l}\text { Reductions in anxiety symptoms were } \\
\text { significantly greater in the IG than the } \\
\text { CG for all children at } 12 \mathrm{~m} \text { (only for } \\
\text { younger children at post-intervention) }\end{array}$ & Sig effect for & $\begin{array}{l}\text { Sig effect } \\
(.69)\end{array}$ & - \\
\hline $\begin{array}{l}\text { Lock \& Barrett } \\
(2003) \text {; Barrett } \\
\text { et al. (2006) }\end{array}$ & $\begin{array}{l}\text { Reductions in anxiety symptoms were } \\
\text { significantly greater in the IG than the } \\
\text { CG at post-intervention and } 12 \mathrm{~m} \text { for both } \\
\text { age groups (maintained at } 24 \mathrm{~m} \text { and } 36 \mathrm{~m} \\
\text { for the younger children only). }\end{array}$ & & $\begin{array}{l}\text { Sig } \\
\text { effect }^{\mathrm{a}}\end{array}$ & $\begin{array}{l}\text { Sig effect } \\
\text { for } \\
\text { younger } \\
\text { children at } \\
24 \mathrm{~m} \& \\
36 \mathrm{~m}^{\text {a }}\end{array}$ \\
\hline $\begin{array}{l}\text { Lowry- Webster } \\
\text { et al. (2003) }\end{array}$ & $\begin{array}{l}\text { Reductions in anxiety symptoms were } \\
\text { significantly greater in the IG than the } \\
\text { CG at post-intervention and } 12 \mathrm{~m} \text {. }\end{array}$ & $\begin{array}{l}\text { Sig effect } \\
\quad(.45)\end{array}$ & $\begin{array}{l}\text { Sig effect } \\
\quad(.53)\end{array}$ & - \\
\hline $\begin{array}{l}\text { Roberts et al. } \\
(2010)\end{array}$ & $\begin{array}{l}\text { No significant differences found between } \\
\text { the IG and the CG at any time point. }\end{array}$ & N.S & - & N.S at $18 \mathrm{~m}$ \\
\hline $\begin{array}{l}\text { Rooney et al. } \\
(2013 a, b) ; \\
\text { Johnstone et }\end{array}$ & 1 & N.S & - & $\begin{array}{l}\text { N.S at } \\
18 \mathrm{~m}, 30 \mathrm{~m} \\
42 \mathrm{~m} \mathrm{\&} \\
54 \mathrm{~m}\end{array}$ \\
\hline $\begin{array}{l}\text { Stallard et al. } \\
(2014)\end{array}$ & $\begin{array}{l}\text { Reductions in anxiety symptoms were } \\
\text { significantly greater in the health } \\
\text { professional-led IG than the CG at } 12 \mathrm{~m} \\
\text { (not for the teacher-led IG). }\end{array}$ & - & $\begin{array}{l}\text { Sig effect } \\
\text { for MHP } \\
\text { IG }(.20)\end{array}$ & - \\
\hline
\end{tabular}

N.S = non-significant effect; ${ }^{\mathrm{a}}=\mathrm{ES}$ could not be calculated; $\mathrm{IG}=$ intervention group; $\mathrm{CG}=$ control group; MHP = mental health professional

Three of the studies reporting 12-month anxiety prevention outcomes compared effects for different aged children. Barrett et al. (2005) and Lock and Barrett (2003) compared the effects for children aged 9-10 and 14-16. Although significant effects were 
reported for all children, slightly greater reductions in anxiety were reported by both studies for the younger children at 12-month follow-up. Essau et al. (2012) reported a mixed picture with greater reductions in anxiety for the 9-10 year olds at post-intervention, but greater reductions in anxiety for the 11-12 year olds at 12-month follow-up. In terms of gender, one study (Lock \& Barrett, 2003) reported that reductions in anxiety over time in the intervention group were greater for females than males. Another study (Barrett, Farrell, Ollendick, \& Dadds, 2006) reported that longer-term anxiety prevention effects stopped by 36 months for females, but were maintained at 36 months for males.

In terms of the three studies that failed to find immediate or long-term anxiety prevention effects, two of these were evaluating the Aussie Optimism Program (AOP) and one was evaluating the E-COUCH program. Given the small number of studies included in this review, it is difficult to offer explanations as to why these studies failed to report longterm anxiety prevention effects. However, it is worth noting that in contrast to the FRIENDS program (where the focus is entirely on anxiety prevention), AOP has a dual focus on anxiety and depression prevention. Both of the AOP studies also evaluated delivery by teachers, whereas most of the FRIENDS studies evaluated delivery by external health professionals or graduates. E-COUCH is unique in the sense that it is the only program included in this review delivered online, and the total intervention hours provided by E-COUCH was also considerably lower than the other studies in this review.

\subsection{Long-term Secondary Prevention Effects}

Two of the five studies included in this review that reported long-term anxiety prevention effects also reported long-term secondary effects. Essau et al. (2012) and Lock and Barrett (2003) reported a significant prevention effect for depression at 12-months follow-up, Essau et al. (2012) also reported significant prevention effects for school-based performance and perfectionism at 12-months follow-up. However, three of the five studies included in this review that reported long-term anxiety prevention effects did not find evidence for long-term secondary prevention effects. None of the studies that failed to find a long-term anxiety prevention effect reported long-term secondary effects. Despite having a dual focus on depression-prevention, the two studies evaluating the AOP also failed to find effects on mood-related measures. 


\section{Discussion}

This systematic review is the first to focus exclusively on the longer-term effectiveness of universally delivered school-based anxiety prevention programs. Eight studies evaluating randomised controlled trials (RCT) with follow-up data of 12-months or beyond were identified, totalling 7522 children aged nine-eighteen years (although several of the studies focused on primary aged children). Each of these studies was evaluating a program based on cognitive-behavioural principles. Although this was not an eligibility requirement, no RCT studies evaluating programs based on other models (e.g., exercise, education alone) could be found that included follow-up periods of 12 -months or beyond.

The hypothesis that a small effect size would be found at the 12-month follow-up for the majority of studies included in this review was largely supported, with five out of the eight studies reporting significant anxiety prevention effects at the 12-month follow-up (Barrett et al., 2005; Essau et al., 2012; Lock \& Barrett, 2003; Lowry-Webster et al, 2003; Stallard et al., 2014). Each of these studies reporting long-term prevention effects was evaluating the FRIENDS program, whilst the three studies that failed to find immediate or longer-term effects were evaluating the AOP and the E-COUCH programs (Calear et al., 2016; Roberts et al., 2010; Rosanna Rooney et al., 2013). This suggests that the short and long-term effects may depend on various factors (including program-type).

Our findings are broadly consistent with the general anxiety prevention literature, which has tended to demonstrate that programs do have small-moderate prevention effect sizes (Teubert \& Pinquart, 2011) and can be delivered in schools (Barrett \& Pahl, 2006). Our finding that not all programs evaluated led to positive prevention effects however, is not atypical either (Ahlen et al., 2015). The anxiety prevention literature has highlighted that program content and delivery is important and has typically demonstrated more support for the FRIENDS program than any other (Fisak et al., 2011), as was found in the current review. Specifically, the results from our review also extend the short-term effects of universal school-based anxiety prevention programs reported by Neil and Christensen (2009) and the tentative conclusions drawn by more recent reviews that the effects of universal anxiety prevention programs can sometimes last beyond six months (Stockings et al., 2016; WernerSeidler et al., 2017).

It is hoped that this review will be useful for public health and education colleagues. Although some of the 12-month follow-up effect sizes are small (ranging from 0.20 to 0.69 ), such changes in the trajectory of anxiety symptomology in school-aged children could have 
wide-ranging benefits if scaled up to population estimates (Nehmy \& Wade, 2014). However, it is important to highlight that the current review found no reliable evidence suggesting that effects endure beyond 12-months. Thus, annual booster sessions are likely to be needed in order to maintain effects. It is also important to highlight that only two studies reported delayed effects at the 12-month follow-up that were not present at post-intervention. Therefore it is unlikely that previous reviews that have relied largely on studies with only short-term follow-up periods have been drastically underestimating the potential longer-term benefits of universal school-based anxiety prevention programs (Neil \& Christensen, 2009).

The current review cannot draw firm conclusions regarding the influence of delivery mode or program content, but each of the five studies that reported long-term prevention effects was evaluating the FRIENDS program (Barrett et al., 1999). It is encouraging that two of these trials were conducted outside of Australia by researchers not involved in the development of the program. The results from one of these studies (Stallard et al., 2014) suggests that external delivery by health professionals may yield better outcomes than internal delivery by teachers. This study also reported 12-month prevention effects without the provision of parent sessions. Previous research is mixed regarding the additive benefit of involving parents in cognitive behavioural treatment (Breinholst, Esbjørn, Reinholdt-Dunne, \& Stallard, 2012) and Essau et al. (2012) found that parent attendance at designated sessions did not impact upon anxiety prevention outcomes. Stallard et al. (2014) also reported a 12month prevention effect without child booster sessions, suggesting that adding these on a yearly basis may be sufficient. Further controlled research will be needed to compare different parent and child booster session options.

Results from another study included in this review (Barrett et al., 2006) suggest that anxiety prevention effects may last longer in younger than older children. Indeed, a previous meta-analysis conducted by Tebert and Pinquart (2011) indicated that anxiety prevention programs are generally less effective for older adolescents. Nehmey and Wade (2014) suggest that programs like FRIENDS, which are largely targeted at primary school children, may need to be adapted for older secondary age children. The current review is not able to draw conclusions regarding the use of online computer technology as a delivery mode because only one study of this nature was included in this review (and reported no immediate or prevention effects).

Finally, few explanations can be offered as to why three of the eight studies included in this review failed to find immediate or long-term anxiety prevention effects. However, this 
review does raise the interesting question as to whether part of the reason the FRIENDS program yielded better results than the AOP program might be because FRIENDS has a primary focus on anxiety prevention whereas AOP has a dual focus on anxiety and depression prevention. Perhaps further research would benefit from testing whether anxiety-specific prevention programs yield better effects than dual-focus or trans-diagnostic programs.

\subsection{Limitations and Conclusions}

In summary, this review suggests that, in some circumstance at least, running the FRIENDS program universally in schools can yield positive long-term effects.. This is encouraging, and although effect sizes were small-moderate (ranging from 0.20 to 0.69 ), could have substantial societal benefits if scaled up to a population level (Nehmy \& Wade, 2014).

However, the results of this review need to be taken with some caution due to a number of limitations. The first is the small number of studies that met eligibility criteria and also the high risk of bias apparent in most of these studies. Secondly, it is a significant limitation that a meta-analysis could not be conducted on the data, meaning few conclusions can be drawn regarding the influence of different factors (e.g., program content, delivery mode) on long-term anxiety prevention outcomes. Further high quality RCTs are needed to address the methodological and theoretical questions raised throughout this review. Indeed, future RCTs need to pay more attention to the criteria outlined by the Cochrane Collaboration 'Risk of Bias' tool (Higgins \& Green, 2011). In particular, allocation concealment, cluster randomisation and random sequence generation methods are needed, along with more detailed reporting of methods, data and analyses. Recent studies in this field have begun to reduce possible sources of bias and have published protocols in advance of the trial (Calear et al., 2016; Stallard et al., 2014), thus allowing for transparent inspection of the data and thorough assessment of study quality.

It is also worth noting that the results of this review are a product of the inclusion criteria established. It is possible that different results may have been found if uncontrolled trials had been included, and this may have also resulted in the inclusion of studies evaluating programs based on non-cognitive behavioural models (such as exercise or education-alone). Further research may be needed to compare cognitive-behavioural programs with other approaches (see Stockings et al, 2016). It is also worth noting that the focus of this review was on anxiety symptomology data (rather than diagnosis), because comparable data were 
available across studies. Further larger-scale research will also need to consider the long-term impact of universal school-based anxiety prevention programs on diagnosis thresholds, which will help inform an economic evaluation.

Finally, previous research also suggests that the FRIENDS program does not always have the desired effect when using it in different contexts, geographical locations and with varying populations (Miller et al., 2011). This review was not able to explore the potential barriers to running anxiety prevention programs in 'real-life' effectiveness conditions. For example, we do not know how effect sizes may have changed if the schools inyolved in the studies reviewed herein had begun integrating the anxiety prevention programs within their curriculums, and in different contexts without the support of researchers with a vested interest in fidelity and controlled conditions. Indeed, program effects typically reduce under the effectiveness conditions of 'usual care' (Marchand, Stice, Rohde \& Becker, 2011).

\section{Declarations}

\section{Funding statement}

This study received no specific funding. This report is independent research and formed part of SW's Doctorate in Clinical Psychology at the University of Bath. The views expressed in this publication are those of the authors(s) and not necessarily those of the NHS.

\section{Competing interests}

The authors declare nocompeting interests.

\section{Author contributions}

SW developed the research question and methodological approach, and also undertook the data analysis and write-up of the article. PS contributed to the development of the research question, and both PS and $\mathrm{CH}-\mathrm{G}$ oversaw the data analysis and write-up. RG contributed to article eligibility screening, data extraction and risk of bias assessment. 


\section{References}

Ahlen, J., Lenhard, F., \& Ghaderi, A. (2015). Universal prevention for anxiety and depressive symptoms in children: A meta-analysis of randomized and cluster-randomized trials. The Journal of Primary Prevention, 36(6), 387-403.

Barrett, P. M., Farrell, L. J., Ollendick, T. H., \& Dadds, M. (2006). Long-term outcomes of an Australian universal prevention trial of anxiety and depression symptoms in children and youth: An evaluation of the friends program. Journal of Clinical Child and Adolescent Psychology, 35(3), 403-411.

Barrett, P. M., Lock, S., \& Farrell, L. J. (2005). Developmental differences in universal preventive intervention for child anxiety. Clinical Child Psychology and Psychiatry, $10(4), 539-555$.

Barrett, P. M., Lowry-Webster, H., \& Holmes, J. (1999). Friends programme: Group leader manual. Brisbane, Australia: Austalian Academic Press.

Barrett, P. M., \& Pahl, K. M. (2006). School-based intervention: Examining a universal approach to anxiety management. Australian Journal of Guidance and Counselling, 16(01), 55-75.

Barrett, P. M. \& Turner, C. (2001). Prevention of anxiety symptoms in primary school children: Preliminary results from a unversal school-based trial. British Journal of Clinical Psychology, 40, 399-410.

Breinholst, S., Esbjørn, B. H., Reinholdt-Dunne, M. L., \& Stallard, P. (2012). CBT for the treatment of child anxiety disorders: A review of why parental involvement has not enhanced outcomes. Journal of Anxiety Disorders, 26(3), 416-424.

Calear, A. L., Batterham, P. J., Poyser, C. T., Mackinnon, A. J., Griffiths, K. M., \& Christensen, H. (2016). Cluster randomised controlled trial of the e-couch Anxiety and Worry program in schools. Journal of Affective Disorders, 196, 210-217. doi:10.1016/j.jad.2016.02.049

Calear, A. L., Christensen, H., Griffiths, K. M., \& Mackinnon, A. (2013). The Y-Worri project: Study protocol for a randomised controlled trial. Trials, 14(1), 76.

Cohen, J. (1988). Statistical power analysis for the behavioral sciences. Hillsdale, NJ: Lawrence Earlbaum Associates. 
Costello, E. J., Egger, H. L., \& Angold, A. (2005). The developmental epidemiology of anxiety disorders: Phenomenology, prevalence, and comorbidity. Child and Adolescent Psychiatric Clinics of North America, 14(4), 631-648. doi:10.1016/j.chc.2005.06.003

Donovan, C. L., \& Spence, S. H. (2000). Prevention of childhood anxiety disorders. Clinical Psychology Review, 20(4), 509-531.

Essau, C. A. (2005). Frequency and patterns of mental health services utilization among adolescents with anxiety and depressive disorders. Depression and Anxiety, 22(3), 130137.

Essau, C. A., Conradt, J., Sasagawa, S., \& Ollendick, T. H. (2012). Prevention of anxiety symptoms in children: Results from a universal school-based trial. Behavior Therapy, 43(2), 450-464. doi:10.1016/j.beth.2011.08.003

Fisak, B. J., Richard, D., \& Mann, A. (2011). The prevention of child and adolescent anxiety: A meta-analytic review. Prevention Science, 12(3), 255-268. doi:10.1007/s11121-011$0210-0$

Gillham, J. E., Shatté, A. J., \& Reivich, K. (2001). Needed for prevention research: Longterm follow up and the evaluation of mediators, moderators, and lay providers. Prevention \& Treatment, 4 , article 9.

Haggerty, R. J., \& Mrazek, P. J.(1994). Reducing risks for mental disorders: Frontiers for preventive intervention research. Washington, DC: National Academies Press.

Hedges, L. V. (1981). Distribution theory for Glass's estimator of effect size and related estimators. Journal of Educational Statistics, 6(2), 107-128.

Higgins, J. P. T., \& Green, S. (2011). Cochrane handbook for systematic reviews of interventions. Retrieved from http://www.cochrane-handbook.org

Kessler, R. C., Berglund, P., Demler, O., Jin, R., Merikangas, K. R., \& Walters, E. E. (2005). Lifetime prevalence and age-of-onset distributions of DSM-IV disorders in the National Comorbidity Survey Replication. Archives of General Psychiatry, 62(6), 593-602. doi:10.1001/archpsyc.62.6.593

Lock, S., \& Barrett, P. M. (2003). A longitudinal study of developmental differences in universal preventive intervention for child anxiety. Behaviour Change, 20(4), 183-199. 
Lowry-Webster, H. M., Barrett, P. M., \& Lock, S. (2003). A universal prevention trial of anxiety symptomatology during childhood: Results at 1-year follow-up. Behaviour Change, 20(1), 25-43.

Masia-Warner, C., Nangle, D. W., \& Hansen, D. J. (2006). Bringing evidence-based child mental health services to the schools: General issues and specific populations. Education and Treatment of Children, 29(2), 165-172.

Marchand, E., Stice, E., Rohde, P., \& Becker, C. B. (2011). Moving from efficacy to effectivness trials in prevention research. Behaviour Research and Therapy, 49, 32-41.

Merry, S. N., Hetrick, S. E., Cox, G. R., Brudevol-Iversen, T., Bir, J. J., \& McDơwell, H. (2011). Psychological and educational interventions for preventing depression in children and adolescents. Cochrane Database of Systematic Reviews, Cd003380.

Miller, L. D., Laye-Gindhu, A., Bennett, J. L., Liu, Y., Gold, S., March, J. S., Olson, B. F., \& Waechtler, V. E. (2011). An effectiveness study of a culturally enriched school-based CBT anxiety prevention program. Journal of Clinical Child \& Adolescent Psychology, 40, 618-629.

Nehmy, T. J., \& Wade, T. D. (2014). Reduction in the prospective incidence of adolescent psychopathology: A review of school-based prevention approaches. Mental Health \& Prevention, 2(3), 66-79.

Neil, A. L., \& Christensen,H. (2009). Efficacy and effectiveness of school-based prevention and early intervention programs for anxiety. Clinical Psychology Review, 29(3), 208215.

Reynolds, S.,Wilson, C., Austin, J., \& Hooper, L. (2012). Effects of psychotherapy for anxiety in children and adolescents: A meta-analytic review. Clinical Psychology Review, 32(4), 251-262.

Roberts, C. M., Kane, R., Bishop, B., Cross, D., Fenton, J., \& Hart, B. (2010). The prevention of anxiety and depression in children from disadvantaged schools. Behaviour Research and Therapy, 48(1), 68-73.

Rooney, R., Hassan, S., Kane, R., Roberts, C. M., \& Nesa, M. (2013). Reducing depression in 9-10 year old children in low SES schools: A longitudinal universal randomized controlled trial. Behaviour Research and Therapy, 51(12), 845-854. 
Rooney, R., Pike, L., \& Roberts, C. (2000). The positive thinking program: Prevention manual (unpublished manuscript). Australia, Curtin University of Technology.

Snyder, J., Bullard, L., Wagener, A., Leong, P. K., Snyder, J., \& Jenkins, M. (2009). Childhood anxiety and depressive symptoms: Trajectories, relationship, and association with subsequent depression. Journal of Clinical Child \& Adolescent Psychology, 38(6), 837-849.

Stallard, P. (2010). Mental health prevention in UK classrooms: The FRIENDS anxiety prevention programme. Emotional and Behavioural Difficulties, 15(1),23-35.

Stallard, P., Skryabina, E., Taylor, G., Phillips, R., Daniels, H., Anderson, R., \& Simpson, N. (2014). Classroom-based cognitive behaviour therapy (FRIENDS): A cluster randomised controlled trial to Prevent Anxiety in Children through Education in Schools (PACES). The Lancet Psychiatry, 1(3), 185-192. doi:10.1016/S22150366(14)70244-5

Stockings, E. A., Degenhardt, L., Dobbins, T., Lee, Y. Y., Erskine, H. E., Whiteford, H. A., \& Patton, G. (2016). Preventing depression and anxiety in young people: A review of the joint efficacy of universal, selective andindicated prevention. Psychological Medicine, 46(1), 11-26. doi:10.1017/S0033291715001725

Teubert, D., \& Pinquart, M. (2011). A meta-analytic review on the prevention of symptoms of anxiety in children and adolescents. Journal of Anxiety Disorders, 25(8), 1046-1059. doi:10.1016/j.janxdis.2011.07.001

Werner-Seidler, A., Perry, Y., Calear, A. L., Newby, J. M., \& Christensen, H. (2017). Schoolbased depression and anxiety prevention programs for young people: A systematic review and meta-analysis. Clinical Psychology Review, 51, 30-47 